\title{
Digital Divides and Online Media
}

\author{
Jukka Ruohonen \\ University of Turku, Finland \\ juanruo@utu.fi
}

\author{
Anne-Marie Tuikka \\ University of Turku, Finland \\ anne-marie.tuikka@utu.fi
}

\begin{abstract}
Digital divide has been a common concern during the past two or three decades; traditionally, it refers to a gap between developed and developing countries in the adoption and use of digital technologies. Given the importance of the topic, digital divide has been also extensively studied, although, hitherto, there is no previous research that would have linked the concept to online media. Given this gap in the literature, this paper evaluates the "maturity" of online media in 134 countries between 2007 and 2016. Maturity is defined according to the levels of national online media consumption, diversity of political perspectives presented in national online media, and consensus in reporting major political events in national online media. These aspects are explained by considering explanatory factors related to economy, infrastructure, politics, and administration. According to the empirical results based on a dynamic panel data methodology, variables representing each aspects are also associated with the maturity of national online media.
\end{abstract}

\section{CCS CONCEPTS}

\section{- Social and professional topics $\rightarrow$ Computing / technology} policy;

\section{KEYWORDS}

Media systems; plurality; freedom of expression; civil rights; developing countries; time-series cross-sectional; comparative research

\section{ACM Reference Format:}

Jukka Ruohonen and Anne-Marie Tuikka. 2021. Digital Divides and Online Media. In Proceedings of ACM Conference (Conference'17). ACM, New York, NY, USA, 7 pages. https://doi.org/10.1145/nnnnnnn.nnnnnnn

\section{INTRODUCTION}

Digital divide is a well-established umbrella concept traditionally used to describe the gap that exists in the adoption, use, and maturity of digital technologies-from personal computers to national network infrastructures-between developed and developing countries. But while in the 1990s the concept was mainly used in terms of access to digital infrastructures-among these the Internet, the concept's scope has widened step by step. Today, there are not only a digital divide, or the digital divide, but digital divides [23]; between countries, between infrastructures, between education

Permission to make digital or hard copies of all or part of this work for personal or classroom use is granted without fee provided that copies are not made or distributed for profit or commercial advantage and that copies bear this notice and the full citation on the first page. Copyrights for components of this work owned by others than ACM must be honored. Abstracting with credit is permitted. To copy otherwise, or republish, to post on servers or to redistribute to lists, requires prior specific permission and/or a fee. Request permissions from permissions@acm.org.

Conference'17, July 2017, Washington, DC, USA

(C) 2021 Association for Computing Machinery.

ACM ISBN 978-x-xxxx-xxxx-x/YY/MM...\$15.00

https://doi.org/10.1145/nnnnnnn.nnnnnnn systems, between disabled and those without impairments [34], between young and old, between genders, and so on and so forth.

The present paper takes a conventional cross-country viewpoint to these digital divides. That said, the paper's context and perspective are both unconventional and novel; the paper is the first to examine a digital divide in terms of online media and its maturity particularly in developing countries. Furthermore, according to a decent literature search from all relevant databases, there is a very limited literature base on media in developing countries. Against this background, to motivate the context and perspective further, a few words should be said more about digital divides and media.

On one hand, these digital divides cast a shadow on popular explanations for the use digital technologies. For instance, the socalled technology acceptance model (TAM) posits that people tend to accept new digital technologies when these are easy to use and benefit their daily work [9]. Although the model has been extended with various other factors, it still tends to undermine socioeconomic factors. When one does not know how to read, or when one is suffering from hunger, ease of use or perceived usefulness of new technologies are supposedly the last thing in one's mind. A similar point applies to online media; even though audiovisual media content is increasingly common, at least a degree literacy is still required to appreciate media in general and journalism in particular. On the other hand, there are certain shortcomings and historical baggage in the digital divide(s) research as well. Although access to the Internet and digital technologies in general continues to be a grave problem in some developing countries, as it was already in the 1990s, in some developing countries Internet access is already on par with developed countries thanks to widespread use of mobile phones $[14,23,24]$. Therefore, the infrastructure is already there for online media at least in some developing countries. A more fundamental point is also present; it is relevant to consider other factors than technology when considering the digital divide(s).

The reasons for not being online are many. Some may not have access, but others may not have money, skills, time, or even need; and others may lack awareness or interests [39]. In other words, digital divide is also a socioeconomic and cultural phenomenon [24]. Access to digital devices and the Internet do not guarantee continuous and productive use of digital technologies and services, which, throughout the world, are increasingly important for citizens to efficiently participate in society and politics [14]. Even in Western countries literature skills, for instance, tend to some extent prevent efficient participation and thus undermine citizens' self-management and self-actualization [31]. As is soon discussed in Section 2, media has an important function in this conundrum.

Although economic rationale is present, media as a system is often seen to also involve societal and educational functions; to enlighten and empower citizens; to reduce prejudices [17]; to provide a public sphere on which societal disagreements and conflicts can

Proceedings of the 5th International Conference on E-Society, E-Education and E-Technology (ICSET 2021), Taipei (online), ACM, pp. 157-163. This is the authors' copy. The publisher's copy is available online via https://doi.org/10.1145/3485768.3485815 
be discussed and mediated; and so on. When considering the emergence of a mature online media system particularly in developing countries, technological and economic factors cannot thus provide a sufficient explanation alone. This point can be further used to criticize the existing technology adoption and evolution models.

Besides the classical TAM model and its adaptations, there is a large number of different maturity models for digital businesses. However, many-if not most-of these models concentrated on organizational and firm-level economic factors, including transactions and business processes [18, 20]. Although online media companies are businesses like other companies, their operating environment is distinctively different from typical e-business companies. While property rights, intellectual rights, and contract law in general are necessary for all businesses [40], media companies typically (but not necessarily) need also civil rights to succeed; freedom of expression, freedom of speech, and media freedom are inherently tied to media and journalism. A media company may succeed economically without these, but the success comes at the cost of sacrificing almost universally held ideals about journalism. These points motivate a societal aspect discussed in the next Section 2. Then, the empirical research design is elaborated in Section 3, results are presented in Section 4, and conclusions follow in Section 5.

\section{A FRAMEWORK}

Digital increasingly intervenes with physical. Not only are new technologies such as artificial intelligence and virtual reality making the boundary blurry for human beings, but the boundary spanning extend toward political economy, geopolitics, and even warfare [33] Also media is entangled in this "mega trend" of digitalization. As a format, traditional print media has long lost to radio, television, and online media sources-including online-only outlets and social media-in most Western countries particularly among the younger generations [21]. Media continues to be in a state of rupture. But traditional media has not stood idle. Most newspapers are available online, new online-only outlets have emerged, and innovative platforms have been developed to enhance journalism in the new digital era. At the same time, large multinational companies are eating media's advertising revenues [30], misinformation, disinformation, and propaganda are rampant online [29], and in many countries local newspapers are struggling [35], media ownership continues to concentrate [11], and public broadcasting media is under a political pressure [10], to only name a few challenges. These are some of the smaller trends behind the digitalization mega trend in Western countries. Elsewhere, in developing countries, the situation may be somewhat different. It is difficult to face digitalization of media when there is a shortage of electricity-to give an extreme example.

How to theorize the maturity of online media particularly in developing countries? To keep things simple, a sensible starting point is to distinguish a societal perspective from an economic perspective to online media. To still simplify, infrastructure can be considered alongside economy, and the societal viewpoint can be broken down to administration and politics. The analytical result is illustrated in Fig. 1. Needless to say, in reality, all of the analytical dimensions intervene; there is no economy without an infrastructure, politics and economy result in political economy, and so forth and so on.

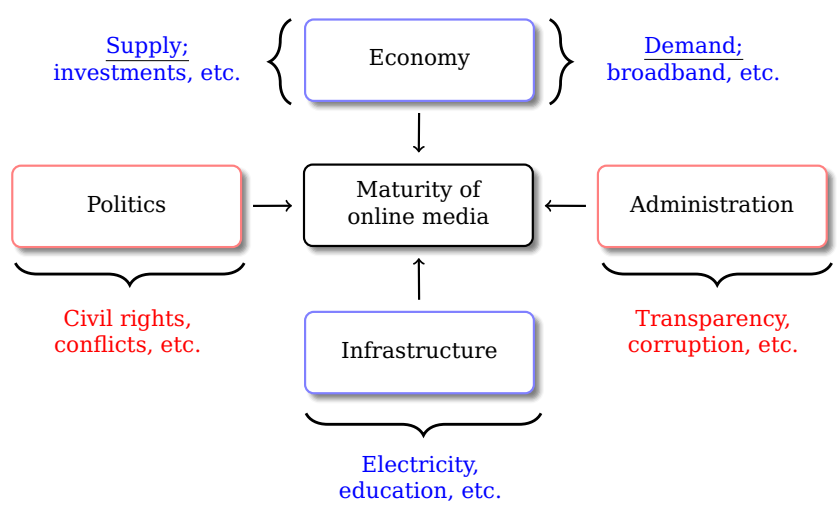

Figure 1: An Analytical Framework

The societal perspective is most of all a normative stance on what media is and should be. This is the question that was asked by Siebert and associates in their classical 1984 monograph Four Theories of the Press ([37]; for the background see also [4, 32]). Although the book starts to show its age, it is still useful for understanding the normative underpinnings. Accordingly, there are four normative theories on the press, and the first is the communist one; a press should ensure the stability of a society by educating and empowering people, although, in practice, the press in past communist countries turned out to be a machinery for propaganda. The second model is an authoritarian press; a press controlled by authoritarian rulers and ran by selected journalists. The third model is the polar opposite; a press that is free from any governmental control akin to the libertarian idea of the "marketplace of ideas." Besides the free exchange of ideas, the theory posits media as a watchdog for the government and ruling elites. The fourth model follows the libertarian ideals but takes also social responsibility into account with aspects such as enlightenment, education, and meditation of societal conflicts. Although none of the models have existed in their pure form, the current Western media systems are located somewhere between the libertarian and social responsibility models. As is typical to classification systems, the four models were later altered and fine-tuned. For instance, the Western media systems have been further broken down to liberal tradition followed in the English-speaking countries, a corporatist system typical to the Nordic countries, and a polarized pluralist system typical to Central Europe [12]. Nevertheless, all of these systems share same universal ideals, among these the freedom of expression, the power and duty to criticize rulers, and many other related ideals.

Against this backdrop, it becomes understandable why digital divide is also a political concept; unstable governments, corruption, lack of transparency and accountability, security and secrecy, and related factors are a reality in many developing countries [38]. Such conditions not only hamper journalism, whether offline or online, but also undermine the more or less universal ideals about media.

These ideals are also taken to reflect the "maturity" of online media. A mature online media should not be only about yellow, paparazzi, or gonzo journalism-even though the digital environment and its engagement dynamics tend to perhaps push journalism 
into this direction. As with the four theories, the normative stance should be acknowledged; taking something like The Intercept as an ideal type is not universally shared even among journalists in the Western countries. That said, some of the ideals-such as the function of a press as a watchdog of ruling elites-are shared also by journalists in many developing countries, although "it is not enough to sail in a turbulent sea with a small boat" [15, p. 31]. There is also a more concrete reason behind this normative maturity notion. Running a media needs money, and money from Western countries-whether through investments, developing aid, or something else-tends to come with the same idealistic strings attached. Some of these strings, such as the freedom of information (but not necessarily expression), have been endorsed also by the United Nations and related organizations since the 1970s onward [28]. Particularly during the heydays of the Cold War, mainstream Western media was typically seen as an essential building block in the development of a well-functioning civil society and thus democracy [19]. While the strings may have loosened, they are still there, partly due to free trade and global regulatory pressure for national media systems [27]. The strings lead to the economic perspective in turn.

On the supply side of economy, a robust infrastructure is required for online media to emerge. While states may supply infrastructures for online media and dictate its content in communist and authoritarian countries, economic incentives and entrepreneurial ambition are required to establish new online media in other countries. In this regard, limited capital, lack of skilled labor, and low tolerance of financial risks have been a long-standing problem particularly for small and medium-sized enterprises in developing countries [2]. Yet infrastructure can be also understood broadly to cover not only economic and technological aspects but also socioeconomic factors, such as education and basic income above extreme poverty.

Indeed, existing studies indicate that income and education are among the most important aspects distinguishing the use of digital technologies in developed and developing countries [14]. These aspects nurture the demand side. If people live in poverty, they are unlikely to pay for online media. Conversely: when people have money and are willing to spend it on online media, there is also a demand for online content. On this demand side, there is not necessarily a notable gap between developed and developing countries-getting people to pay for online content is a problem everywhere. This problem is further associated with the iron grip of multinational technology companies who, too, have not stood idle; in many developing countries, the Internet and Facebook are synonyms [36]. Besides all other problems and obstacles, the Big Tech entanglement does not at least make things easier for those attempting to build online media outlets in developing countries.

\section{RESEARCH DESIGN}

\subsection{Data}

The dataset assembled covers $n=134$ countries and $t=10$ years, spanning a period between 2007 and 2016. The assembling was done with the goal of keeping the amount of missing values at minimum. Although some countries and years had to be thus dropped, the coverage across the world is good, as can be concluded from Fig. 2.

Two data sources were used: the World Bank's online data portals and the varieties of democracy (V-Dem) project. The latter source

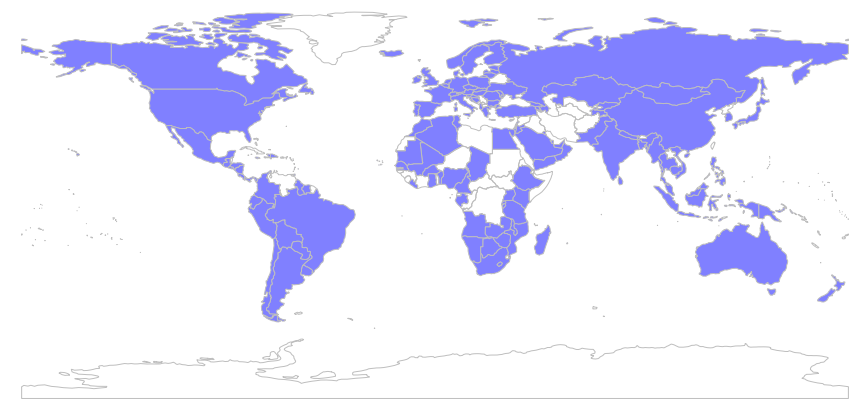

Figure 2: Countries Covered in the Dataset

has been widely used in social sciences (see [16, 29], among others), and for a good reason; currently, the V-Dem project provides the most comprehensive comparative dataset on democracy, civil liberties, digital society, and related phenomena. The data is supposedly also robust, as exemplified the lack of missing values, which, unfortunately, are a problem with the World Bank data even after deleting many country-year pairs. Following recent research [32], these missing values were interpolated with cubic splines [1].

\subsection{Dependent Variables}

Three dependent variables are used [5, pp. 325-326]. The first is the consumption of online media by domestic audiences. In the V-Dem dataset this variable is measured with a four-item Likert-scale: (0) no one consumes domestic online media; (1) limited consumption of domestic online media; (2) relatively common consumption of domestic online media; and (3) almost everyone consumes domestic online media. Like many variables in the dataset, it is converted to an ordinal scale that resembles z-values; the value zero approximates the mean of all country-year pairs of the variable in the V-Dem dataset [7, pp. 24-25]. With this scaling, indeed, the variable's empirical distribution resembles the normal distribution even after the necessary removal of countries, as can be concluded from the topmost plot in Fig. 3. Negative values indicate infrequent consumption of domestic online media, whereas large positive values correspond with a well-consumed online domestic media. In the sample used the most consumed domestic online media are located in Sweden, South Korea, Canada, the United Kingdom, and Iceland.

The second dependent variable measures the diversity of political perspectives expressed in online media. Again, a four-item Likert scale is used (before scaling): (0) only a government's perspectives are represented; (1) also perspectives of semi-official, governmentapproved opposition are represented; (3) there is at least one major online outlet representing all perspectives important to a society; (4) there are many outlets representing a wide array of perspectives. When looking at the middle plot in Fig. 3, the interpretation is fairly straightforward with respect to non-democratic countries.

The third and final dependent variable asks a question about whether major domestic online outlets represents a major political event similarly. Before scaling, this question is yet again answered with a four-item Likert scale: major outlets (1) give opposing views; (2) differ greatly in their reporting of major political events; (3) sometimes agree; (4) mostly agree; and (5) there are only small differences in reporting of big political events. Thus, the variable measures 

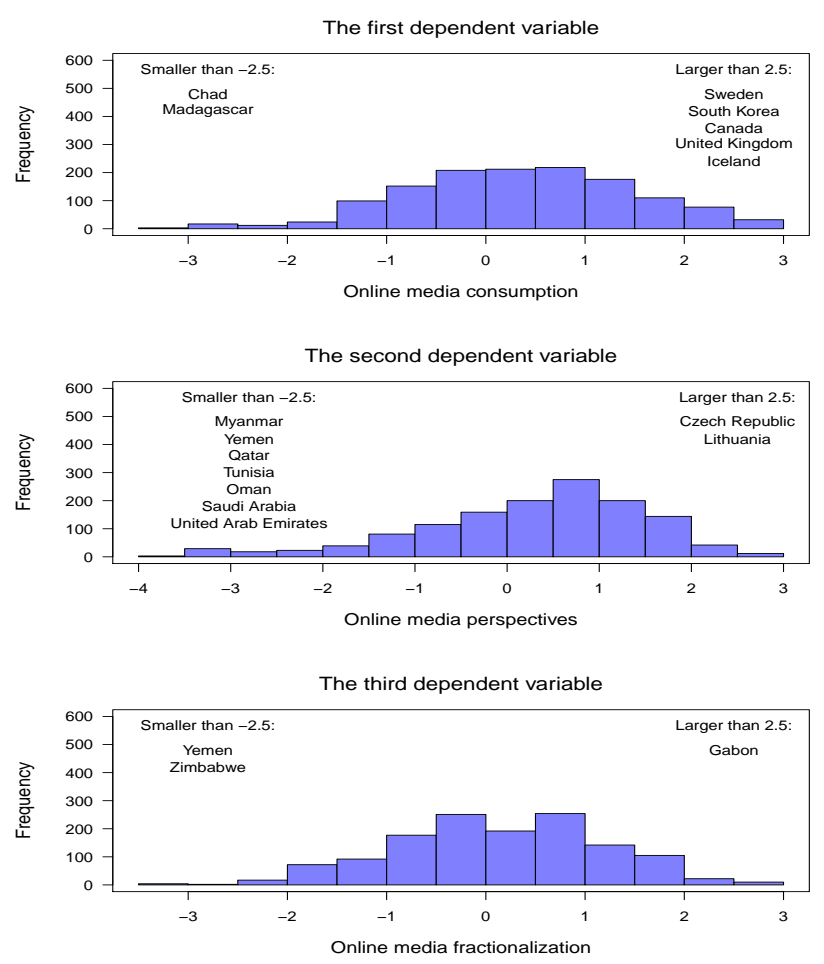

Figure 3: Presence of Online Media

political consensus of online media; the higher a value, the higher the consensus. Alternatively: because major newspapers are statecontrolled in many authoritarian countries, reporting mainly in line of political establishments, more divergence may be found from online outlets. When looking at the countries with low and high scaled scores in Fig. 3, either interpretation seems plausible.

The three variables are assumed to represent different viewpoints on the maturity of an online media ecosystem in a given country. When online media is well-established and widely consumed, it represents also a plurality of different political viewpoints, and so forth. Statistically, however, the variables are unrelated; the maximum correlation coefficient between the three variables is only 0.33. This lack of forceful statistical dependence justifies modeling of the three variables separately even though they are understood to be parts of the same underlying online media maturity concept.

\subsection{Independent Variables}

The independent variables are enumerated in Table 1 within which the third column refers to the online source from which a given dataset was retrieved. That is to say, the primary source may differ for some of the World Bank's datasets. For instance, the International Telecommunication Union is the primary data source for the fixed broadband and mobile cellular subscription amounts. The grouping of the variables aligns with the analytical framework in Fig. 1; each group is represented by four carefully selected variables.

The economic and infrastructure variables have been widely used in previous research $[25,26]$. It is therefore more relevant to make few remarks about the operationalization of the variables. The variables from the World Bank's TCdata360 portal [45], such as those for corruption or government transparency, are scalar-valued indices whose values range from one to seven; the higher a value, the better the outcome; a value seven implies an unlikely case that no corruption whatsoever is present in a country, for instance.

The political variables from the V-Dem project [5] require a more thorough elaboration. The variable for liberal democracy is a composite index, constructed from four individual variables. It measures the protection of minority groups and individuals against the tyranny of the state and the majority; higher values indicate more liberalism. The freedom of expression variable, too, is a composite index measuring press freedom, academic and cultural expression, as well as the freedom of people to discuss political issues at home and in public spaces. Political arrest measures the likelihood that a citizen will be arrested upon posting political content online. A four-item Likert-scale is used: an arrest is (0) extremely likely, (1) likely, (2) unlikely, or (3) extremely unlikely. The removal of online content by a government, in turn, is measured with a five-item scale: (0) any content can be removed at will; (1) law protects only politically uncontroversial issues; (2) legal ambiguity exists for removal; (3) political speech is mostly protected yet politically controversial content may be removed; (4) a law protects all political speech such that a government can only remove content according to rigorous legal criteria. By hypothesis, at least one of these political variables should be associated either with the perspectives dependent variable or the fractionalization dependent variable, or both.

\subsection{Methods}

The dataset's nature is time series cross-sectional data, but, since $n>t$ to a fair margin, panel data is a better characterization. The classical estimator for such data is ordinary least squares augmented with dummy variables for the years and countries. In addition to problems with accuracy [22], as manifested in the covariance structure and thus standard errors of the regression coefficients, the least squares estimator ignores all longitudinal dynamics; autocorrelation in the error term is thus another problem. Adding a lagged dependent variable is an option, but it leads to additional problems.

To address these issues, the dynamic Arellano-Bond panel data estimator [3] is used, as implemented in an R package [8]. Essentially, the estimator uses a lagged dependent variable and first differences to get rid of the constant $(\alpha)$ and the cross-sectional effects $\left(c_{i}\right)$, such that in a toy model with only one independent variable, an equation $y_{i t}=\alpha+\beta_{1} y_{i t-1}+\beta_{2} x_{i t}+c_{i}+\epsilon_{i t}$ becomes $\Delta y_{i t}=\beta_{1} \Delta y_{i t-1}+\beta_{2} \Delta x_{i t}+\Delta \epsilon_{i t}$. This, however, creates a moving average process to the error term, which the estimator accounts for with instrumental variables. For the models estimated, the second, third, and fourth lags are used as instruments for the lagged dependent variable as well as all independent variables. In addition, lagged differences, $\Delta x_{i t-1}$, are added for the independent variables.

As for basic diagnostic checks, first-order autocorrelation (AR) should be present but second-order should be absent; a test developed by Arellano and Bond [3] is provided by the implementation used. And as for practical estimation, a $\ln (x+1)$ is transformation is applied to all independent variables that do not attain negative 
Table 1: Independent Variables (refer to Fig. 1 for the analytical motivation)

\begin{tabular}{lllr}
\hline Variable & Category & Description & Retrieval source \\
\hline GDP & Economy & GDP per capita (current US\$) & {$[43]$} \\
FDI & Economy & Foreign direct investment inward flows (\% GDP) & {$[42]$} \\
Procurement & Economy & Government procurement of advanced technology products & {$[45]$} \\
State economy & Economy & State control of important sectors of economy & {$[6]$} \\
Electricity & Infrastructure & Electricity and telephony infrastructure & {$[45]$} \\
Education & Infrastructure & Quality of the education system & {$[45]$} \\
Broadband & Infrastructure & Fixed broadband subscriptions & {$[41]$} \\
Mobile & Infrastructure & Mobile cellular subscriptions & {$[44]$} \\
Rule of law & Administration & Enforcement and compliance with laws & {$[6]$} \\
Accountability & Administration & Accountability of a government & {$[6]$} \\
Transparency & Administration & Transparency of a government's policy-making & {$[45]$} \\
Corruption & Administration & Ethics and corruption & {$[45]$} \\
Liberal democracy & Politics & Extent of liberal democracy & {$[6]$} \\
Freedom of expression & Politics & Freedom of expression of media and people & {$[6]$} \\
Political arrests & Politics & Arrests due to political online content & {$[6]$} \\
Content removal & Politics & Government removal of online content & {$[6]$} \\
\hline
\end{tabular}

values. Finally, nine additional dummy variables are included for annual effects, although these are not reported for brevity. due to legal protections, there are also less disagreements in reporting major political events in online media.

\section{RESULTS}

The regression results are summarized in Table 2, which shows three models corresponding with the three dependent variables. The basic diagnostic checks hold for all models; the null hypotheses of no second-order autocorrelation hold. Wald's tests indicate that the coefficients are jointly statistically significant in all models. Thus, to proceed, the models can be briefly disseminated as follows:

(1) Three coefficients are statistically significant in the first model. These are: GDP per capita, inward FDI flows, and the transparency of governments' policy-making processes. The signs of the corresponding coefficients are also positive, as was expected. Though, the magnitude of the coefficient for the FDI variable is too small to warrant specific attention. When people have more money, the demand for online media increases, and when a government is transparent, there is more for journalists to report and readers to read.

(2) Two coefficients are statistically significant in the second model: political arrests and governments' removal of online content. When recalling the operationalization (see Section 3.3), the positive signs for the coefficients are also as expected. When there is no fear of being arrested for reporting multiple viewpoints, the plurality of perspectives expressed in online media increases. Analogous reasoning applies when a government rarely removes online content.

(3) Three coefficients are statistically significant in the third model. The first is the one for education quality, which has a positive sign, which seems reasonable. The second one for broadband subscriptions has a negative sign, however, which seems illogical or at least unexpected. The third is again for the coefficient of the content removal variable. Thus: when removal of political content by a government is unlikely
These results align with prior expectations and seem sensible in general, excluding the one negative sign noted. Although statistical significance is hardly the only (or even the right) way to proceed with statistical inference, what may seem a little surprising is the lack of statistically significant effects for many of the variables. For instance, the other coefficients for the infrastructure variables are not statistically significant even at the conventional $p<0.05$ level. Alternative model specifications do not change the situation. A potential explanation for the lack of statistically significant effects for the infrastructure variables relates to the noted fact that the infrastructure already exists in many countries. When considering the second and third models, the perspectives and fractionalization, it may also be that the infrastructures are already too good in some countries with communist or authoritarian media systems. In other words, the surveillance capabilities in many countries may well establish a certain deterrence effect [29], leading to self-censorship that may curtail press freedom and thus decrease the plurality of political viewpoints by journalists in online media. Besides these speculations, there is a potential statistical explanation.

It should be also recalled that the models estimated are dynamic panel data models, and the magnitudes of the lagged dependent variables indicate a high degree of persistence. A general lack of longitudinal variance has been observed also previously with the V-Dem data [32]. Furthermore, Wald's $\chi^{2}$-tests indicate that the dummy variables for annual effects are not jointly statistically significant in the second and third models. These points can be used to argue that the situation has remained mostly unchanged in the 20072016 period observed. Nevertheless, to interpret the results against the framework in Fig. 1, there is enough evidence to conclude that economy, state administration, and politics (but not necessarily infrastructure) contribute to the maturity of online media. 
Table 2: Regression Results

\begin{tabular}{|c|c|c|c|}
\hline & \multicolumn{3}{|c|}{ Dependent variable $\left(y_{i t}\right)$} \\
\hline & Consumption & Perspectives & Fractionalization \\
\hline$\Delta y_{i t-1}$ & $0.578^{* * *}$ & $0.259^{* * *}$ & $0.560^{* * *}$ \\
\hline$\Delta \ln (\mathrm{GDP}+1)_{i t}$ & -0.119 & -0.057 & 0.038 \\
\hline$\Delta \ln (\mathrm{GDP}+1)_{i t-1}$ & $0.343^{* *}$ & 0.102 & -0.071 \\
\hline$\Delta(\mathrm{FDI})_{i t}$ & $<0.001$ & $<0.001$ & $<0.001$ \\
\hline$\Delta(\mathrm{FDI})_{i t-1}$ & $0.002^{* *}$ & $<0.001$ & $<0.001$ \\
\hline$\Delta \ln (\text { Procurement }+1)_{i t}$ & -0.001 & 0.017 & -0.023 \\
\hline$\Delta \ln (\text { Procurement }+1)_{i t-1}$ & 0.039 & -0.005 & -0.010 \\
\hline$\Delta(\text { State economy })_{i t}$ & -0.085 & 0.064 & 0.033 \\
\hline$\Delta(\text { State economy })_{i t-1}$ & 0.069 & 0.140 & -0.095 \\
\hline$\Delta \ln (\text { Electricity }+1)_{i t}$ & 0.096 & -0.011 & 0.011 \\
\hline$\Delta \ln (\text { Electricity }+1)_{i t-1}$ & -0.047 & -0.036 & 0.017 \\
\hline$\Delta \ln (\text { Education }+1)_{i t}$ & 0.001 & 0.098 & 0.024 \\
\hline$\Delta \ln (\text { Education }+1)_{i t-1}$ & 0.035 & 0.022 & $0.031^{* *}$ \\
\hline$\Delta \ln (\text { Broadband }+1)_{i t}$ & -0.018 & 0.009 & 0.003 \\
\hline$\Delta \ln (\text { Broadband }+1)_{i t-1}$ & 0.011 & 0.002 & $-0.032^{* * *}$ \\
\hline$\Delta \ln (\text { Mobile }+1)_{i t}$ & -0.288 & 0.030 & -0.024 \\
\hline$\Delta \ln (\text { Mobile }+1)_{i t-1}$ & 0.120 & 0.010 & 0.087 \\
\hline$\Delta \ln (\text { Rule of law }+1)_{i t}$ & 1.098 & 1.386 & 0.470 \\
\hline$\Delta \ln (\text { Rule of law }+1)_{i t-1}$ & -0.984 & -1.045 & 0.329 \\
\hline$\Delta \ln (\text { Accountability }+1)_{i t}$ & 0.060 & -0.021 & -0.017 \\
\hline$\Delta \ln (\text { Accountability }+1)_{i t-1}$ & -0.051 & 0.101 & -0.020 \\
\hline$\Delta \ln (\text { Transparency }+1)_{i t}$ & $0.530^{* *}$ & 0.157 & -0.437 \\
\hline$\Delta \ln (\text { Transparency }+1)_{i t-1}$ & -0.370 & -0.153 & 0.273 \\
\hline$\Delta \ln (\text { Corruption }+1)_{i t}$ & -0.044 & -0.168 & 0.078 \\
\hline$\Delta \ln (\text { Corruption }+1)_{i t-1}$ & -0.013 & 0.062 & -0.139 \\
\hline$\Delta \ln (\text { Liberal democracy }+1)_{i t}$ & 0.102 & -0.412 & -0.739 \\
\hline$\Delta \ln (\text { Liberal democracy }+1)_{i t-1}$ & -0.446 & 0.007 & -0.186 \\
\hline$\Delta \ln (\text { Freedom of expression }+1)_{i t}$ & 0.206 & 0.153 & -0.058 \\
\hline$\Delta \ln (\text { Freedom of expression }+1)_{i t-1}$ & -0.011 & -0.753 & 0.344 \\
\hline$\Delta(\text { Political arrests })_{i t}$ & -0.002 & $0.377^{* * *}$ & 0.049 \\
\hline$\Delta(\text { Political arrests })_{i t-1}$ & 0.002 & 0.017 & -0.062 \\
\hline$\Delta \ln (\text { Content removal }+1)_{i t}$ & -0.059 & $0.595^{* * *}$ & $0.519^{* * *}$ \\
\hline$\Delta \ln (\text { Content removal }+1)_{i t-1}$ & 0.158 & -0.060 & -0.227 \\
\hline $\mathrm{H}_{0}:$ no $\mathrm{AR}(1), p$-values & $<0.001$ & $<0.001$ & $<0.001$ \\
\hline $\mathrm{H}_{0}:$ no $\mathrm{AR}(2), p$-values & 0.334 & 0.564 & 0.765 \\
\hline
\end{tabular}

\section{CONCLUSION}

This paper examined the maturity of online media in time series cross-sectional framework covering 134 countries in a period spanning ten years. Maturity was defined according to consumption of online media, political perspectives expressed in online media, and fractionalization of online media in terms of reporting major political events. A simple four-dimensional analytical model (economics, infrastructure, administration, and politics) was used to motivate the empirical analysis. Based on dynamic panel data estimator, at least one variable belonging to each dimension was statistically significant in explaining the three concepts of maturity; namely, GDP per capita, inward FDI flows, transparency of governmental administration, potential arrests due to political online content, content removal by a government, education, and broadband subscriptions. All in all, the results align with the prior theoretical speculations.

But, by design, the time series cross-sectional research setup can only touch the surface of the question of online media maturity. While sensible for the setup, particularly the independent variables only indirectly proxy the underlying analytical dimensions in Fig. 1. To gain a more realistic perspective, survey methodology would be more suitable in order to gain explicit answers about the challenges and obstacles for building new digital media particularly in developing countries. But then again, obtaining longitudinal data with a global scope from surveys is an extremely difficult task without substantial resources. Given this backdrop, it seems sensible to recommend that further work should be done to quantify 
more variables in existing time series cross-sectional data frameworks such as V-Dem. For instance, public service media has been observed to be an important factor explaining the diversity of perspectives expressed in national media systems [13], and quantifying the existence of public broadcasting should be a relatively easy task.

Public broadcasting and public service media in general are good examples also from another perspective. Government intervention has been argued to be necessary to bridge a digital divide in many developing countries [24]. On one hand, this point can be taken to reflect critically on the ideals of libertarian media systems in English-speaking countries. It may be that economic opportunities and civil liberties are not enough for a new online media system to emerge; the corporatist model in the Nordic countries may be a viable option. On the other hand, particularly in developing countries the dangers of state control are real; having too much government involvement may turn toward the communist and authoritarian media system types via which the freedom of expression and other civil liberties may be endangered. Every coin has two sides. Finally, it is worth noting that a decade may be too short-after all, the evolution of the printing press toward maturity took centuries.

\section{ACKNOWLEDGMENTS}

This paper was partially funded by the Strategic Research Council at the Academy of Finland (grant number 327391).

\section{REFERENCES}

[1] H. Akima, A. Gebhardt, T. Petzold, and M. Maechler. akima: Interpolation of Irregularly and Regularly Spaced Data. R-package version 0.6-2.1, available online in June 2021: https://cran.r-project.org/web/packages/akima/index.html, 2020.

[2] W. Anderson. Internationalization Opportunities and Challenges for Small and Medium-Sized Enterprises from Developing Countries. Journal of African Business, 12:198-217, 2011.

[3] M. Arellano and S. Bond. Some Tests of Specification for Panel Data: Monte Carlo Evidence and an Application to Employment Equations. The Review of Economic Studies, 58(2):277-297, 1991.

[4] J. Clarke. News Media Systems in Developing Countries: How the Models are Working out in Cambodia. Media Asia, 33(3-4):142-149, 2006.

[5] M. Coppedge et al. V-Dem Codebook v11.1. Varieties of Democracy (V-Dem): Global Standards, Local Knowledge, available online in June: https://www.v-dem. net/en/data/reference-material-v11/, 2021

[6] M. Coppedge et al. V-Dem Dataset - Version 11.1, Country-Year: V-Dem Full+Others. Varieties of Democracy (V-Dem): Global Standards, Local Knowledge, available online in June: https://www.v-dem.net/en/data/data/ v-dem-dataset-v111/, 2021.

[7] M. Coppedge et al. V-Dem Methodology v11.1. Varieties of Democracy (V-Dem): Global Standards, Local Knowledge, available online in June: https://www.v-dem.net/media/filer_public/4e/1c/ 4e1c47ae-4800-436a-bbf1-c5fb50798bd3/methodology_v111.pdf, 2021.

[8] Y. Croissant and G. Millo. Panel Data Econometrics in R: The plm Package. fournal of Statistical Software, 27(2):1-43, 2008.

[9] F. D. Davis. Perceived Usefulness, Perceived Ease of Use, and User Acceptance of Information Technology. MIS Quarterly, 13(3):319-340, 1989.

[10] S. Dawes. Broadcasting and the Public Sphere: Problematising Citizens, Consumers and Neoliberalism. Media, Culture \& Society, 36(5):702-719, 2014.

[11] A. Grisold. Press Concentration and Media Policy in Small Countries: Austria and Ireland Compared. European fournal of Communication, 11(4):485-509, 1996.

[12] D. Hallin and P. Mancini. Comparing Media Systems: Three Models of Media and Politics. Cambridge University Press, Cambridge, 2004.

[13] E. Humprecht and F. Esser. Diversity in Online News: On the Importance of Ownership Types and Media System Types. Journalism Studies, 19(2):1825-1847, 2017.

[14] H. Karar. Algorithmic Capitalism and the Digital Divide in Sub-Saharan Africa. fournal of Developing Societies, 35(4):514-537, 2019.

[15] M. M. Khan and S. Islam. Democracy and Good Governance in Bangladesh: Are They Compatible? Millennial Asia, 5(1):23-40, 2014.

[16] A. Lewczuk. Are Civil Liberties Contagious? Analysis of Determinants of de facto Civil Rights Protection in Post-Socialist Countries. Constitutional Political Economy, 32:187-217, 2021.
[17] S. Lissitsa and N. Kushnirovich. Harnessing Digital Media in the Fight Against Prejudice: Social Contact and Exposure to Digital Media Solutions. Fournalism \& Mass Communication Quarterly, 96(4):1052-1075, 2019.

[18] A. V. Looy, M. De Backer, G. Poels, and M. Snoeck. Choosing the Right Business Process Maturity Model. Information \& Management, 50(7):466-488, 2013.

[19] J. Miller. NGOs and 'Modernization' and 'Democratization' of Media: Situating Media Assistance. Global Media and Communication, 5(1):9-33, 2009.

[20] E. P. Morais, J. A. Pires, and R. M. Gonçalves. E-Business Maturity: Constraints Associated With Their Evolution. Journal of Organizational Computing and Electronic Commerce, 22(3):280-300, 2012.

[21] N. Newman, R. Fletcher, A. Schulz, S. Andli, and R. K. Nielsen. Reuters Institute Digital News Report 2020. Reuters Institute \& University of Oxford, available online in June 2021: https://reutersinstitute.politics.ox.ac.uk/sites/default/files/ 2020-06/DNR_2020_FINAL.pdf, 2020.

[22] S. Nickell. Biases in Dynamic Models with Fixed Effects. Econometrica, 49(6):14171426, 1981

[23] P. Norris. Digital Divide: Civic Engagement, Information Poverty, and the Internet Worldwide. Cambridge University Press, Cambridge, 2001.

[24] A. O. Odongo and G. C. Rono. Kenya Digital and Cultural Divide. In Proceedings of the 9th International Conference on Theory and Practice of Electronic Governance (ICEGOV 2015-16), ICEGOV '15-16, pages 85-94, Montevideo, 2016. ACM.

[25] J. B. Pick and R. Azari. Worldwide Digital Divide: Influences of Education, Workforce, Economic, and Policy Factors on Information Technology. In Proceedings of the 2007 ACM SIGMIS CPR Conference on Computer Personnel Research: The Global Information Technology Workforce (SIGMIS CPR 2007), pages 78-86, St. Louis, 2007. ACM.

[26] J. B. Pick and T. Nishida. Digital Divides in the World and Its Regions: A Spatial and Multivariate Analysis of Technological Utilization. Technological Forecasting and Social Change, 91:1-17, 2015.

[27] M. Puppis. National Media Regulation in the Era of Free Trade: The Role of Global Media Governance. European fournal of Communication, 23(4):405-424, 2008.

[28] M. Rooy. Developing Media in Developing Countries: A Historical Review of Policies. Gazette, 24(1):2-10, 1978.

[29] J. Ruohonen. A Comparative Study of Online Disinformation and Offline Protests. Archived manuscript, available online: http://arxiv.org/abs/2106.11000, 2021.

[30] J. Ruohonen. A Critical Correspondence on Humpty Dumpty's Funding for European Journalism. Archived manuscript, available online: https://arxiv.org/ abs/2011.00751, 2021.

[31] J. Ruohonen. Assessing the Readability of Policy Documents on the Digital Single Market of the European Union. In Proceedings of the Eighth International Conference on eDemocracy \& eGovernment (ICEDEG 2021), Quito, 2021. IEEE.

[32] J. Ruohonen. Reassessing Measures for Press Freedom. Archived manuscript, available online: http://arxiv.org/abs/2106.10427, 2021.

[33] J. Ruohonen. The Treatchery of Images in the Digital Sovereignty Debate. 2021. Archived manuscript, available online: https://arxiv.org/abs/2012.02724.

[34] N. Sachdeva, A.-M. Tuikka, K. K. Kimppa, and R. Suomi. Digital Disability Divide in Information Society. Journal of Information, Communication and Ethics in Society, 13(3-4):283-298, 2015.

[35] P. Sands. Fighting for Funding: UK Newspapers Editors Talk About the Pressures on Local Newspapers in Britain Today. Index on Censorship, 48(1):42-44, 2019.

[36] M. Shearlaw. Facebook Lures Africa With Free Internet - But What Is the Hidden Cost? The Guardian, available online in June 2021: https://www.theguardian.com/ world/2016/aug/01/facebook-free-basics-internet-africa-mark-zuckerberg, 2016.

[37] F. S. Siebert, T. Peterson, and W. Schramm. Four Theories of the Press: The Authoritarian, Libertarian, Social Responsibility, and Soviet Communist Concepts of What the Press Should Be and Do. University of Illinois Press, Urbana and Chicago, 1984.

[38] P. Thorpe. The Impact of New Information Technology in the Developing Countries. Fournal of Information Science, 8(5):213-220, 1984.

[39] E. Vartanova. Digital Divide and the Changing Political/Media Environment of Post-Socialist Europe. Gazette, 64(5):449-465, 2012.

[40] O. E. Williamson. Comparative Economic Organization: The Analysis of Discrete Structural Alternatives. Administrative Science Quarterly, 36:269-296, 1991.

[41] World Bank. Fixed Broadband Subscriptions. Available online in June: https: //data.worldbank.org/indicator/IT.NET.BBND, 2021.

[42] World Bank. Foreign Direct Investment, Net Inflows (\% of GDP). GovData360 portal, available online in June: https://data.worldbank.org/indicator/BX.KLT. DINV.WD.GD.ZS, 2021.

[43] World Bank. GDP per capita (current US\$). GovData360 portal, available online in June: https://data.worldbank.org/indicator/NY.GDP.PCAP.CD, 2021.

[44] World Bank. Mobile Cellular Subscriptions. Available online in June: https: //data.worldbank.org/indicator/IT.CEL.SETS, 2021.

[45] World Bank. TCdata360. Available online in June: https://tcdata360.worldbank. org/, 2021 